This item was submitted to Loughborough's Research Repository by the author.

Items in Figshare are protected by copyright, with all rights reserved, unless otherwise indicated.

\title{
Information availability at the competitive bidding stage for service contracts
}

PLEASE CITE THE PUBLISHED VERSION

http://dx.doi.org/10.1108/JMTM-05-2012-0059

PUBLISHER

(c) Emerald

VERSION

AM (Accepted Manuscript)

LICENCE

CC BY-NC-ND 4.0

REPOSITORY RECORD

Kreye, Melanie E., Yee M. Goh, and Linda B. Newnes. 2019. "Information Availability at the Competitive Bidding Stage for Service Contracts”. figshare. https://hdl.handle.net/2134/10875. 
This item was submitted to Loughborough's Institutional Repository (https://dspace.lboro.ac.uk/) by the author and is made available under the following Creative Commons Licence conditions.

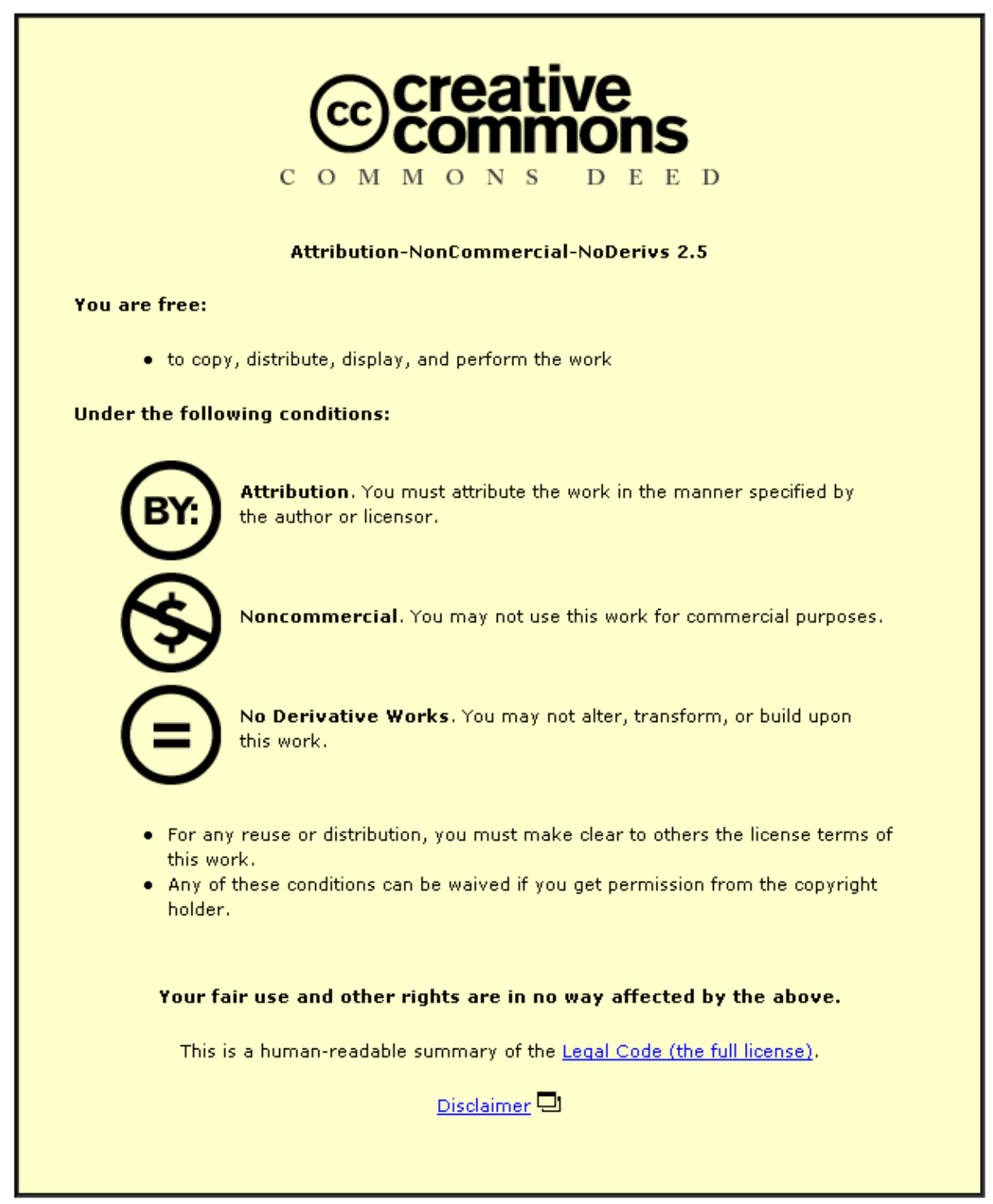

For the full text of this licence, please go to: http://creativecommons.org/licenses/by-nc-nd/2.5/ 


\section{Information availability at the competitive bidding stage for service contracts}

\section{Introduction}

Sustainable production and consumption have become more important internationally which has led to the transformation of market structures and competitive situations into the direction of servitisation [Baines et al., 2011; Bandinelli and Gamberi, 2011]. For a manufacturing company the shift towards being a service provider is characterised by a high level of uncertainty about the future strategic development of the company caused by e.g. inadequate knowledge and information [Song et al., 2007]. For this research, a service is defined as an activity or a process which is aimed at the change of the state of the service issue such as the repair of a machine or the supply of flying hours for an aircraft [Araujo and Spring, 2006; Gadrey, 2000].

In this context, the supply of product-centred services becomes more important. These services tend to be long-lived. For example, Babcock announced their support contract for the Australian Anzac class surface ship fleet until 2023 [Babcock, 2012]. Another example is Rolls-Royce’s Flotilla Support Programme for their submarines until 2017 [Rolls-Royce, 2011]. The shift to a being a supplier for these services can cause many uncertainties, especially for companies that have previously focused on the production and manufacturing of products.

The delivery of a service is usually embedded in a contract which is an agreement between the parties about the technical details of the service and is intended to be legally binding [Nellore, 2001; Rowley, 1997]. Service contracts are often allocated through the process of competitive bidding where the competing suppliers communicate their service specifications and price bid to the customer who then evaluates the bids [Rexfelt and Ornäs, 2009; Bubshait and Almohawis, 1994]. This bidding process can include different levels of 
negotiation with the customer which can vary from an auction type bid [Friedman, 1956; Neugebauer and Pezanis-Christou, 2007] to an elaborate information exchange process [Lehman, 1986; Bajari et al., 2008]. These varying levels of negotiation leave the bidding supplier with different levels of uncertainty influencing the pricing decision process.

The pricing approach that is applied most frequently in practice is the cost-based pricing process which puts the starting point of the research at the estimation of the costs of the service contract [Hytönen, 2005]. Cost estimation is concerned with predicting the future, thus, uncertainty is inherent to the process [Goh et al., 2010; Christoffersen, 1998]. This uncertainty can be included in the cost estimate in different ways, one possibility is the range or density forecast which consists of a range of possible future values [Tay and Wallis, 2000]. Included in the range forecast can be the minimum, maximum and average value connected to different assumptions about the future [Giordani and Söderlind, 2003]. An exemplary cost estimate is depicted in Figure 1. At the bidding stage, the decision maker has to select one point within the given range as a price bid to communicate to the customer; one example is marked in Figure 1.

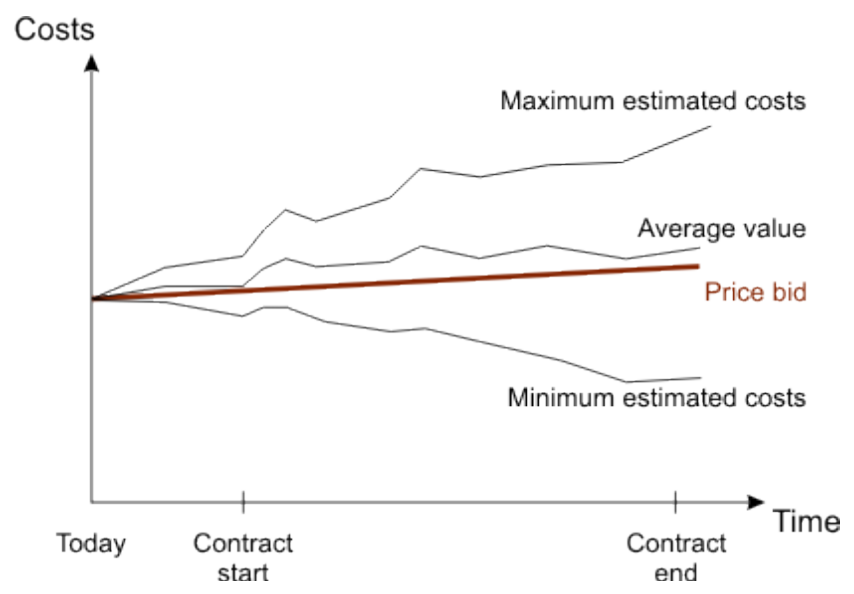

Figure 1: Example of a cost estimate and the possible price bid

Choosing a price that is too high may result in being underbid by competitors and, thus, potential loss of the business [Lucas and Kirillova, 2011; Chapman et al., 2000]. A too low price may influence the customer's perception of the quality of the service and, thus, be 
rejected [Freedman, 1988] or the failure to recover the costs and profit of the service [Swinney and Netessine, 2009; Wang et al., 2007]. For the pricing decision at the bidding process the decision maker has to i) understand the uncertainty in the cost estimate and ii) understand other uncertainties that influence the bidding success and the fulfilment of the service contract.

The aim of this paper is to identify the availability and use of information at the competitive bidding stage. For this, an interview study with industrialists from different sectors was conducted. The related literature in contract bidding including the bidding process, contract conditions and typical payment methods is described in Section 2. Sections 3 and 4 describe the interview study and its results.

\section{Bidding for contracts}

Most literature describing theory on bidding decisions focus on auction-type processes [Cai et al., 2009; Schoenherr and Mabert, 2008; Neugebauer and Pezanis-Christou, 2007]. This means that the described approaches focus on a constrained bidding environment and low complexity and duration of the services discussed in this context [Schoenherr and Mabert, 2008]. This means that the model and theories described have limited applicability to the research described in this paper. This research focuses on services of high complexity, which are typically embedded in contracts of long duration.

Literature describing the decision-making processes at the competitive bidding stage typically focuses on products [Li and Graves, 2012; Bhaskaran and Ramachandran, 2011; Sošić, 2011; Li and Wang, 2010]. Particularly the pricing decisions of products has been highlighted to be influenced by uncertainty [Sošić, 2011]. For example, customers can be expected to evaluate the competitive bids according to an individual list of preferences [Chaneton and Vulcano, 2011; Guo et al., 2009]. Reasons for this more elaborate body of 
literature in product-focused decision making may be the longer history of the business process in industry and the issues connected to it.

However, approaches describing the pricing of services can be found in the literature. One example is described by Guo et al. [Guo et al., 2009], who model the strategic decision in a single-supplier context. While the approach offers valuable insights into the decisionmaking processes, it has two limitations for the application to servitisation: (i) it does not include the existence of competition at its influence on the bidding strategy and (ii) it describes services of low complexity such as hotel accommodation or restaurant dining.

It can be summarised that current literature offers limited insights into the strategic decision-making processes at the competitive bidding stage, particularly from an industrial viewpoint. In particular, they do not consider the information that is available and the strategic process of its consideration in industry. Research that fails to consider these aspects will fail to accurately represent the decision-making process at the competitive bidding stage and will not be adopted by industry. This paper aims at closing this gap by introducing an exploratory study which describes the availability of information at the competitive bidding stage and its strategic consideration in practice.

\section{Method}

The aim of this study was to explore the availability of relevant information in the context of competitive bidding for a service contract on the supplier's side and to describe the subjective processes of the decision maker at the bidding stage. To examine this aim, an interview study was conducted. The following sections describe the applied method of this study in more detail. First, the interview procedure is described, then the design of the interview with the questions is explained, and last, the number of interviewees and the for example the sectors they work in are then described. 


\subsection{Interview procedure}

A standardised interview was carried out meaning the wording and sequence of questions was determined in advance, thus, each interviewee was asked the same questions in the same order [Teddlie and Tashakkori, 2009]. This ensured that all topics were covered in each interview allowing a comparison between the answers of the different interviewees [Patton, 2002]. The questions were open-ended, i.e. no predetermined answers were given (or suggested) and the interviewees were encouraged to describe the processes in their own words. This reduced possible bias of the replies. The interviews were not recorded as most of the interviewees were from organisations of the defence sector or simply not comfortable with recording. The results are based on the notes the researcher took during the interview processes. However, to ensure the correctness and limit the misinterpretation of the given information, the responses were returned to the interviewees after the interview for confirmation and validation as explained in [Robinson et al., 2007].

\subsection{Questionnaire design}

The questionnaire design was based both on previous empirical work and the literature in the field. The empirical work focused on two experimental studies undertaken with a total of 72 cost engineers and bidding decision makers from practice. These studies focused on the different influences on the bidding decision-making process, including the approach of displaying the cost estimate [Kreye et al., 2012] and the influence of the existence of competition on the decision outcome and rationale [Kreye, 2011]. The participants were given a set of questionnaires which consisted of a pricing scenario and various questions connected to their decision-making process for this hypothetical example.

From the answers in the experimental studies it became clear, that industry did not have a universal set of definitions for the terminology. Thus, it was decided that in the 
beginning of the interview, the participant's specific definition had to be clarified and established.

The literature highlights the influence of contextual issues to the pricing decision. These are for example the contract situation within the company [Monroe, 2002; Chapman et al., 2000], the bidding process [Lehman, 1986] and the payment process [Tseng et al., 2009]. Thus, the decision context was the focus of the second area of interview questions.

In the experimental studies preceding the interview, one of the questions focused on the further influences on the decision-making process. The answers to this question could be categorised into market uncertainties (which included developments such as inflation, economic changes and technology development), cost estimation uncertainty, product uncertainties (including performance of the machine and risk of failures), Competition uncertainty (manifesting itself in the risk of losing the contract) and Customer uncertainties. These five main influences were used as a basis for the interview questionnaire, in particular to establish the amount of information typically available about these issues.

As the bidding decision making is highly influenced by strategic considerations [Harrington Jr., 2009; Afuah, 2009], the fourth area of interview questions focused on the bidding strategy. Based on the literature in the field, it was found that different influences are of importance. For example, due to the highly subjective nature of decision making, the choice of the bidding decision maker has been highlighted as an important factor [Tulloch, 1980]. Further influences include the decision maker's interpretation of the cost estimate by based on his/her experience and assumptions [Kreye et al., 2012] and the calculation of the price bid [Hytönen, 2005; Monroe, 2002; Lehman, 1986].

Thus, it can be summarised that the design of the interview questionnaire was based on an iterative process of combining results of preceding empirical studies with industry and 
the literature in the field. Based on this process, the interview questionnaire was compiled which is described in the following section.

\subsection{Interview questionnaire}

The questions covered four main areas: uncertainty and risk, bidding context, input information for the pricing decision, and bidding strategy. Questions included in the first main area established the meanings the practitioners applied to the terms risk and uncertainty and how these are considered and identified in the pricing process. These established a common ground for the terminology in comparison to the definitions applied in the presented research and formed the basis for later questions.

The second main area about the bidding context established background information that can potentially influence the bidding strategy. The issues investigated were the current contract situation of the company [Monroe, 2002; Chapman et al., 2000], the usual bidding process for service contracts [Lehman, 1986] and the typical payment method once the contract was awarded [Tseng et al., 2009].

The last two areas form the main focus of the interviews. The area of the input information for the pricing decision examined the form and type of information normally used in the decision process and possible assumptions the decision maker may form [Goh et al., 2010; Bolton et al., 2006; Fargier and Sabbadin, 2005; Rubinstein, 1998; Loewenstein and Prelec, 1993; Lehman, 1986]. The questions in this area examined; the form of the cost estimate, the uncertainties included in the cost estimate, possible further uncertainties that the decision maker considers in the pricing process, the available information about the competitors and the customer, and the amount of input information that is considered in the decision making process.

The area of bidding strategy established the subjective aspects of decision making in the competitive bidding situation as this may influence the outcome of the decision process 
[Kreye et al., 2012; Stecher, 2008; Yager, 1999; Lehman, 1986; Tulloch, 1980]. The questions explored; the selection process of the decision maker, the interpretation of the cost estimate, the calculation of the price bid, the calculation of the minimum price bid, and the possibility of accepting contracts with a high risk of making a loss. The next sub-section describes the participants of this empirical study.

\subsection{Interviewees}

The interviews were carried out over one year (March 2010 to March 2011) during a rebound period after the global economic recession of 2008-2009. Nine interviews were undertaken where the investigated sectors and numbers of interviewees were:

- Defence (1), aerospace (1) and Both defence \& aerospace (2),

- Engineering (2),

- $\quad$ Research (1),

- Information technology (1),

- Construction (1).

The interviewed companies ranged from large and globally acting providers (with employee numbers varying between about 40,000 and 1,800 employees) to smaller, nationally acting providers (with less than 300 employees). The group of interviewees focused on the suppliers of product-centred services with varying levels of complexity. The contract complexity describes its value with a fuzzy distinction of its attributes, in other words there is no distinct value or factor that defines the difference between the two complexity grades. Thus, the service contracts included in this interview study were separated as follows;

- Low complexity: the number of independent tasks necessary to complete the service and divergence is the difference between the natures of these tasks is low [Skaggs and 
Youndt, 2004; Shostack, 1987]. In other words, the requirements are clear to the involved parties [Bajari et al., 2008]. The interviewees of this study named these “small contracts” and characterised them using phrases such as "less than $£ 3$ million”, "less than 150.000 Euro", or "simple requirements such as the need of three engineers to do some testing”.

- High complexity: the number of independent tasks necessary to complete the service and divergence is the difference between the natures of these tasks is high [Skaggs and Youndt, 2004; Shostack, 1987]. In other words, at the point of the bid invitation, the service design may be hard to define in detail [Bajari et al., 2008]. The interviewees named these "large contracts" and distinguished the with phrases such as "more than $£ 3$ million”, “complex tasks such as 18 months contract” or “site management”.

Table 1 shows the frequency of answers from the interviewees. Four of the nine interviewees said they hold a portfolio of different complexity contracts, two focused on contracts of low complexity and three interviewees concentrated on contracts of high complexity.

Table 1: Interviewees’ positioning regarding the size of their service contracts

\begin{tabular}{|l|c|c|}
\hline & \multicolumn{1}{|c|}{ Low } & $\begin{array}{c}\text { High } \\
\text { complexity }\end{array}$ \\
\hline Contract focus & 2 & 3 \\
\hline Contract portfolio & \multicolumn{2}{|c|}{4} \\
\hline
\end{tabular}

\subsection{Methodology for result analysis}

To analyse the responses, a qualitative approach was applied. This means the results and their implications are discussed verbally to highlight the importance in the bidding and pricing process [Saunders et al., 2012]. Nevertheless, to demonstrate the relative importance of specific answers, a quantitative presentation of these results was chosen for specific questions. This is included mainly for demonstration purposes to show where trends may emerge. Due to the limited number of interviewees, a complete statistical analysis of these trends was not 
possible and is not included in this paper.

In general, the basis for the data analysis was the differentiation of the interviewees depending on the size of their service contracts as described in Section 3.4. However, when the interviews showed a relationship between questions or even interview areas, this relationship is emphasised in the data analysis. For example, a connection was found between the included uncertainty in the cost estimate, the approach to communicating this cost estimate (both questions concerning the input information) and the decision maker's interpretation of this estimate (question asked in connection to the bidding strategy). This relationship is analysed in one section. To demonstrate when these cross-relationships were found in the interview process, Figure 2 depicts the data collection methodology in contrast to the analysis methodology.

\section{Data collection methodology}

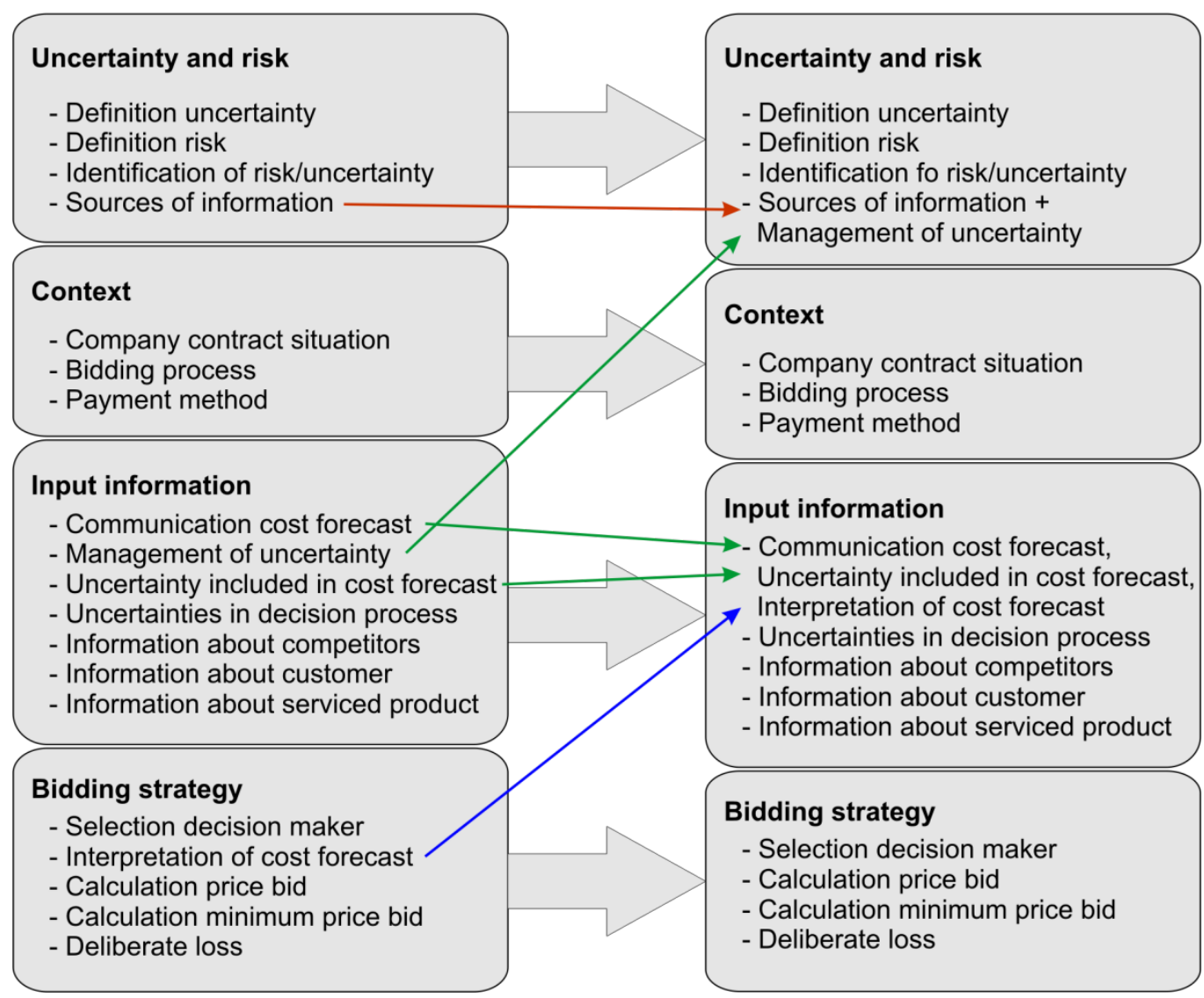

Figure 2: Comparison of data collection and analysis methodologies 


\section{Results}

This section analyses the results of the interview study and presents them in the four main areas, namely uncertainty and risk, bidding context, input information, and bidding strategy. The term bidding strategy refers to the pattern of activities which has an impact on the achievement of bidding goals such as winning a profitable contract.

\subsection{Uncertainty and risk}

The aim of the questions in this section was to clarify the terminology used by the industrialists and thus to guide further discussion of the topic. Differences could be observed between the interviewees in general. Some had corporate-wide definitions for the two terms; others used examples to describe their individual understanding, two interviewees did not use the term uncertainty. However, comparing the meaning or interpretation of the definitions, similarities can be found. Out of nine interviewees, seven understood uncertainty as the variation of an aspect of the contract such as the cost estimate.

Discussing the term risk, the interviewees agreed that it is connected to an impact. Furthermore, seven interviewees stated that it was connected to a specific event, such as the risk of a red light during a car journey or the loss of a team member whose knowledge is central to the fulfilment of the service. Two interviewees described it as the impact on the project as a whole. The interviewees' definitions of the terms risk and uncertainty were utilised throughout the process of interviewing as a basis for clarity. However, for the purpose of this research, the described definition of uncertainty (see list of definitions) is applied in the further analysis of the interview results; the concept of risk is not discussed further.

The interviewees' sources of identification and management tools for uncertainty can be classified based on the level of subjectivity. To identify the uncertainty connected to a project, all interviewees identified experience as the main source which was typically 
connected to the team that put the bid together (stated by six interviewees) or to the project manager (stated by three interviewees). In addition, more objective identification sources were used such as a formalised risk analysis process in the form of e.g. a risk management handbook or databases of previous projects. This category was mentioned by four interviewees. For the identification of uncertainties, the practitioners used either a subjective method on its own or in combination with an objective method.

To manage uncertainty, subjective approaches were of less importance than for the identification; only five interviewees named this approach. Four interviewees mentioned objective management methods out of which three also mentioned objective identification methods. Table 2 depicts the connection between the classification of information sources and management tools for uncertainty. The frequencies highlight the amount of times each individual aspect was mentioned and thus do not add up with the combinatorial numbers in the rest of Table 2.

Table 2: Interviewees' responses regarding sources of information and management tools of uncertainty in the decision process at the bidding stage

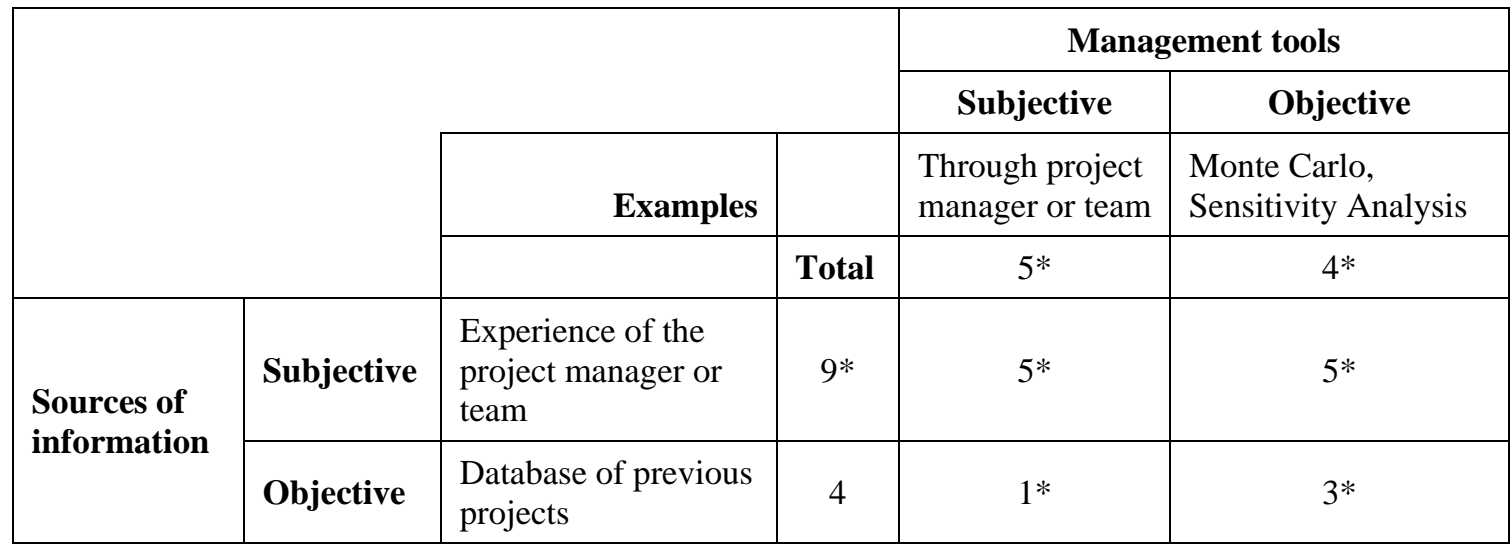

* these values do not sum up as combinations of subjective and objective methods were stated.

\subsection{Bidding context}

Describing the bidding process, the interviewees' answers were categorised into four groups: one-bid process, two-bid process without negotiation, two-bid process with negotiation, and negotiation. In the one-bid process, the competitors have one opportunity to submit their bid 
including the bid price and the specifications of the service and the contract. The customer then evaluates these bids and agrees to one of the offers. This includes the assumption that the customer has the ability to understand the technical and commercial details of the bids.

In the two-bid process without negotiation, the bidding process is split into two phases. In the first phase, a number of possible suppliers submit their bid which usually includes their suitability for the service contract (this can be based on an invitation to bid or an open access). This number of competitors is reduced to the most suitable ones who are then invited to submit their full bid in the second phase. In this second phase, the competitors typically know the identity of each other. None of the phases includes negotiation with the customer.

In the two-bid process with negotiation, the bidding process is split into two phases similar as described above. However, the second phase is characterised by a negotiation between the competitors and the customer to clarify important issues and questions. The answers to these questions can be published to all competitors or stay confidential between the two negotiating parties.

A bidding process which includes negotiation is characterised by an exchange of large amounts of information concerning the service requirements, the customer's intention, technical scope or any other issues concerning the contract or bid.

The bidding process which the interviewees typically faced in their decision process depended on the size of the contract to be bid for. The definitions as described in Section 3.3 are used to describe the contract size. Table 3 depicts the answer frequency of the usual bidding process connected to the contract size. The values in Table 3 distinguish between usual and possible bidding processes as indicated by the interviewees. The numbers do not add up to nine as multiple answers were given by the interviewees managing a contract portfolio. 
Table 3: Characterisation of bidding process regarding the type of contract to be bid for

\begin{tabular}{|c|c|c|c|c|c|}
\hline & \multicolumn{4}{|c|}{ Level of information exchange } \\
\hline & & \multicolumn{3}{|l|}{ Auction } & Negotiation \\
\hline & & $\begin{array}{l}\text { One-bid } \\
\text { process }\end{array}$ & $\begin{array}{c}\text { Two bid process } \\
\text { without negotiation }\end{array}$ & $\begin{array}{l}\text { Two bid process } \\
\text { with negotiation }\end{array}$ & Negotiation \\
\hline \multirow{2}{*}{$\begin{array}{l}\text { Size of } \\
\text { contract }\end{array}$} & \multirow{2}{*}{$\begin{array}{l}\text { fow } \\
\text { complexity } \\
\text { High } \\
\text { complexty }\end{array}$} & $\begin{array}{l}\text { Possible: } 4 \\
\text { Usual: } 2\end{array}$ & $\begin{array}{l}\text { Possible: } 1 \\
\text { Usual: } 1\end{array}$ & - & - \\
\hline & & - & - & Usual: 3 & Usual: 5 \\
\hline
\end{tabular}

The results of Table 3 indicate that low complex contracts with clear requirements are typically not negotiated which can be constituted with the reason that negotiation is a time and cost consuming process [Bajari et al., 2008]. In contrast, contracts of high complexity are typically agreed after negotiation with varying levels of depth of this process. This suggests that the uncertainty that may arise from unclear requirements can usually be reduced by collecting further information from the customer. The parties were willing to commit additional time and costs to this process to ensure that the service outcome best fits the needs of each of them.

The interviewees' answers regarding the usual payment methods for service contracts can be divided into three categories: fixed price, cost-based payment and payment on completion. Seven of the nine interviewees stated that (some of) their company's service contracts are paid with fixed prices which can be based on milestones (mentioned by four) or over a set period of time (stated by three interviewees) such as a monthly payment. Three of the interviewees stated that the payment is based on the actually spent costs which can be assessed through e.g. timesheets. In the category of payment on completion, the service supplier is paid upon completion of the project which was mentioned by one interviewee. It is to be noted that this company offered research services which usually only have deliverables at the end of the service period in the form of e.g. a research report. 
Multiple answers were possible. Based on these results it can be summarised that fixed price payment seemed to be the standard method for service contracts. The following section describes the input information of a pricing decision.

\subsection{Input information}

The results of the interviewees' answers to the questions of the input information section were analysed in three main sections: cost estimate and uncertainty, customer and competitors. These are described in this section.

\subsubsection{Cost estimate and uncertainty}

The way the cost estimate is communicated during the bidding process was found to be distinguishable into two categories: presented using a table or a graph. The costing information included in a table was found to be in two different ways. Four interviewees used a detailed cost breakdown in the form of the necessary work steps, the time and expertise needed for each step and the cost value assigned to the different steps. The other approach was mentioned to include a 3-point-estimate which includes pessimistic, most likely and optimistic assumptions represented in a tabular form. The approach that was used most to include cost estimating information in a graph was a 3-point estimate. Another approach mentioned was an s-curve which displays the cumulative costs over time and usually adopts the form of the letter S (see e.g. [Cioffi, 2005]).

The specification of the available costing information in practice was found to be influenced by the way uncertainty was included in the estimate. The levels of uncertainty included in the cost estimate were reported as: none, variation in the input data and quantification of qualitative uncertainty. Four interviewees stated that they included no uncertainties in their cost estimate. In the second group, the available information that the cost estimate is based on can vary; for example, to fulfil a specific task, a particular engineer may 
have taken 4 or 5 hours depending on other variables. The third group includes the assessment of the question of 'what can go wrong' and connecting a value to this assessment. This occurs subjectively through the experience of the decision maker.

Furthermore, the interpretation of the cost estimate was found to be dependent on the way uncertainty was included in the cost estimate, thus it is discussed in this section (this question was asked in connection to the bidding strategy). The answers were grouped as: none, a point estimate and a range estimate. Participants who stated that they included no uncertainties in their cost estimate also said that the cost estimate they received was not interpreted. This means the cost estimate was taken as it was. However, two of those said that the possibility was kept in mind that the cost estimate may be reduced due to the fact that it was based on conservative values. For example, if the historic data would show that a specific task took between 4 and 5 hours, the cost estimate would be based on the 5-hour estimate. If the final cost estimate would be considered too high, these cost values would be adjusted in a second iteration of the process.

In the second category, the costing information with the related uncertainty was stated to be interpreted as a point estimate, based on e.g. the $50 \%$ or $80 \%$ line in the graph. One interviewee stated that this was only held up when the uncertainty connected to the contract was low, otherwise a cost range was kept. In the third category, the communicated costing information was carried forward in the pricing process as a range estimate, either with its original spread or as a reduced spread. One interviewee stated that the full range was utilised when there was high uncertainty connected to the contract in the form of a high variation in the input data.

Table 4 shows the comparison of the way the cost estimates were presented and interpreted against the uncertainty that is included. The total values do not add up to nine because two interviewees stated the use of multiple methods to communicate their cost 
estimate; one used both types of graphical displays, the other one stated the use of tables to present the cost breakdown and graphs to present the overall costs. However, the total values give an indication of how often each type of presentation was mentioned and which uncertainty is included.

As depicted in Table 4, the companies that presented the cost estimate as a breakdown in a table did not include any uncertainty; it was rather based on specific assumptions. These assumptions included the choice of a conservative value when the input data varied, e.g. when a task was recorded to take between 4 and 5 hours, the estimate would be based on 5 hours. Furthermore, when uncertainty was included, the cost estimate was more likely to be presented in graphical form. All interviewees who stated that they used a graphical approach to display their costing information included uncertainty in it.

Table 4: Appearance of cost estimate in dependence of included uncertainty

\begin{tabular}{|c|c|c|c|c|c|c|}
\hline & & & \multirow[b]{3}{*}{ Total } & \multicolumn{3}{|c|}{ Included uncertainty } \\
\hline & & & & None & $\begin{array}{l}\text { Variation in } \\
\text { input data }\end{array}$ & $\begin{array}{l}\text { Quantification of } \\
\text { uncertainty }\end{array}$ \\
\hline & & & & 4 & 3 & 4 \\
\hline & & $\begin{array}{c}\text { Cost } \\
\text { breakdown }\end{array}$ & 4 & 4 & - & - \\
\hline Presentation of & & $\begin{array}{l}\text { 3-point } \\
\text { estimate }\end{array}$ & 1 & - & - & 1 \\
\hline cost estimate & & $\begin{array}{l}\text { 3-point } \\
\text { estimate }\end{array}$ & 4 & - & 3 & 2 \\
\hline & & s-curve & 1 & - & - & 1 \\
\hline & & None & 4 & 4 & - & - \\
\hline $\begin{array}{l}\text { Interpretation of } \\
\text { cost estimate }\end{array}$ & As po & nt estimate & 4 & - & 3 & 1 \\
\hline & As ran & ge estimate & 2 & - & 1 & 1 \\
\hline
\end{tabular}


The interviews also assessed which further uncertainties can influence the pricing decision. Two out of the three interviewees who stated that their cost estimate did not contain any uncertainties, also stated there were no further uncertainties influencing the pricing decision. Both of them, however, stated that they would reduce the cost estimate if the originally derived price bid would be considered as too high. The other uncertainties influencing the pricing decision were categorised into: customer related uncertainties, competitor related uncertainties, cost estimation uncertainties, economic uncertainties and others.

Customer related uncertainties included the customer's previous choices of bidders for similar projects to recognise observable patterns. For example the customer may always go for the price bid that is $5 \%$ below their stated budget limit. Other factors were mentioned as the assessment of questions such as the possible consequences if the customer found a mistake in the bid, the location of the customer to evaluate the possible travel costs, and assumptions about the usage of the serviced product or machine. Another aspect that was mentioned was the level of experience of the customer's personnel involved in the usage of the product or machine that was part of the service contract. Further aspects related to the customer are analysed at a later point in this section.

Competitor related uncertainties assessed the identification of the competitors for the particular service contract and an evaluation of their most likely bid. Furthermore, the contract might be let to multiple suppliers who would either focus on different aspects of the service or would have to be able to share the project. Further aspects related to the competitors are analysed at a later point in this section.

As discussed in this section, the cost estimate was stated to either include different uncertainties in the form of a spread or was based on assumptions that may not prove true. Further uncertainties included the possibility of cost reductions through e.g. a reduction of the overhead costs. 
Economic uncertainties include factors which may influence the commercial activities such as legal changes, gains that can be achieved with the contract, the situation of the overall economy, of the market place and of the specific sector.

Other mentioned uncertainties included the bidding company's contract situation and the uncertainty arising from the technical requirements. Most interviewees mentioned more than one of the presented sources of uncertainty with a clear emphasis on one important factor, usually concerning an example from the recent past. For this reason, there is no quantitative analysis of the relative importance of each of the mentioned categories.

\subsubsection{Customer}

The available information concerning the customer considered the areas of their bidding strategy, the past relationships, their future needs and whether these aspects influence the decision maker of the bidding company. For these interviews, the customer's bidding strategy was addressed through the aspect of their budget and their evaluation criteria regarding the bids. The interviewees' answers indicate two different categories: either these strategic aspects are communicated with the service requirements or they can be assessed through a "getting to know the client” process in which usually a commercial team is involved. Of the nine interviewees, four stated that the customer's bidding strategy was communicated, two said it could be assessed, and three that it varies between these two categories depending on the kind of customer (resulting from aspects such as if they had worked with them before, what the preferred bidding process of the customer was).

The past relationship between the bidding company and the customer was described by all interviewees as an important source of information. An ideal bidding situation would involve a long past relationship where trust had been build up and the parties would know each other. When this is not the case, the bidding company may still have previous experience with the customer to build up knowledge about them. In cases where there is no previous 
experience, the bidding company has to rely on the information communicated by the customer themselves or published in e.g. the press.

The assessment of the customer's possible future needs caused different reactions with the interviewees. One part (seven of nine interviewees) stated that this was one aspect that they assess during the process of compiling the bid and included it if appropriate. These interviewees stated the importance of possible follow-up work, future relations and the length of the service contract to demonstrate the suitability for e.g. the next five years. The other two interviewees highlighted that the bid only covered the service requirements and that a consideration of the customer's possible future needs was highly speculative and thus not included in the bid-compiling process. Thus, for a specific competitive bidding situation, the customer's future needs may play an important role in the bidding process and would need to be considered in a conceptual framework of the influencing uncertainties at the bidding stage.

Regarding the consideration of the available information about the customer, all interviewees stated that it was of importance for the decision maker and the compiling of the bid. Five said that all the available information is considered, two described the customer and their bidding strategy as the most important influence on the bid, and two stated that there were other more important aspects such as the contract costs. This means that the customer can constitute a central factor in a bidding decision, however, its relative importance depends on the particular service contract.

\subsubsection{Competitors}

The interviewees were asked questions which aimed at determining the following information regarding their competitors, namely; their identity, their cost estimate, their available technology or knowledge, and which of these aspects would be considered in the pricing decision. 
As indicated in the discussion in Section 4.2, the identity of the competitors may be known depending on the bidding process. If this is not the case, the bidding company may either have a 'pretty good' idea regarding their competitors, due to their experience about who is capable of dealing with the requirements or not be able to identify them at all, particularly when trying to bid in new market segments where their experience is limited. For the purpose of this analysis, the three possibilities are named as the competitors' identity is known, knowable or not known.

The competitors' cost estimates are not usually known to the bidding company which was confirmed by all interviewees. However, there are different levels of speculation. Based on previous experiences, a 'ballpark' or top level deduction may be known which can be formulated as an absolute value or assessed in relation to the bidding company's costs. Another possibility is the knowledge of cost details such as salaries based on information obtained from previous employees of the competitor. In other cases, particularly when dealing with new or unknown competitors, the cost estimates may be neither known nor deducible.

The third investigated aspect concerned the information about the competitors' available technology or level of knowledge which may give them a competitive advantage. The answers varied between three categories. A common answer (by six out of nine interviewees) was that it is known as the competitors advertise themselves on e.g. the internet and their homepages or have other publicity in e.g. newspapers. Two interviewees stated that this aspect of the competitors is knowable due to the decision maker's experience in the area. In other cases, particularly when the company bids in a new market segment, this aspect was stated to be not known and not knowable by two interviewees.

Table 5 shows the frequency of the interviewees' answers for their knowledge of the competitors' cost estimates and their available technology or knowledge plotted against the competitors' identity. The numbers do not sum up to nine due to the fact that four 
interviewees stated multiple answers regarding the competitors' identity which can be dependent on the particular service contract. Hence their answers varied also for the other aspects.

The results shown in Table 5 give an indication to the availability of information about the competitors and thus the level of uncertainty connected to them. In cases where the competitors' identity is known or determinable, the bidding company also had a reasonable level of knowledge about other aspects. In other words, the bidding company is not ignorant about their competitors and their possible bidding strategies unless it is bidding in a new market sector.

Table 5: Available information about the competitors at the bidding stage

\begin{tabular}{|c|c|c|c|c|c|}
\hline & & \multicolumn{3}{|c|}{ Identity of competitors } \\
\hline & & \multirow[b]{2}{*}{ Total } & Known & Knowable & Not known \\
\hline & & & 7 & 7 & 2 \\
\hline \multirow{3}{*}{$\begin{array}{l}\text { Value of competitors' } \\
\text { cost estimates }\end{array}$} & Top level costs & 6 & 6 & 6 & - \\
\hline & Cost details & 2 & 2 & 2 & - \\
\hline & No & 2 & 1 & 2 & 2 \\
\hline \multirow{3}{*}{$\begin{array}{l}\text { Competitors' } \\
\text { availability of } \\
\text { technology and/or } \\
\text { knowledge }\end{array}$} & Known & 6 & 6 & 4 & - \\
\hline & Knowable & 3 & 2 & 3 & - \\
\hline & Not known & 2 & - & - & 2 \\
\hline
\end{tabular}

Investigating the interviewees' consideration of these aspects during the decision process, six replied that they used all the information that is available to them and two stated that they considered the available information but that there are other more important factors such as the customer. One interviewee said that the information regarding the competitors is not considered in the pricing-decision process. This confirms the results of the second empirical study, namely that competition is one of the influences on a pricing decision. Furthermore, most of the interviewed companies (seven out of nine) stated that it was one of the most important factors. 
Similarly, the availability of the original service and contract requirements was assessed with the interview as they would have been communicated by the customer at the beginning of the bidding process. They were stated by all interviewees to be available and included in the decision process. The following section describes the interviewees' answers regarding their bidding strategy.

\subsection{Bidding strategy}

The interviewees' answers to the questions concerning the bidding strategy were analysed in three main sections: The choice of the decision maker, the method to obtain the price bid and the acceptance of a contract with a high risk of making a loss. These are described in this section.

\subsubsection{Choice of the decision maker}

As the bidding strategy can be very subjective, the interview assessed how the decision maker was chosen. Most of the interviewees (seven out of nine) highlighted that the decision was made by a team; two stated that a team was involved in the bid compilation and the final decision was made by the team manager. The team decision was connected to contracts of both low and high complexity; four of the seven interviewees managed contract portfolios, one dealt with contracts of low complexity and two focused on ones of high complexity. Thus, it can be derived that the assignment of a team to the decision process is not correlated with the contract size. This means that team dynamics may influence the decision outcome and that the uncertainty caused by human behaviour which is connected to one individual decision maker is of minor importance in this context.

The decision makers were chosen based on different criteria: experience, delegation and completed courses. Multiple replies were possible. In the first group, the decision maker(s) would be chosen based on their experience with bidding in general, bidding for 
similar contracts or in managing (similar) service contracts. In the second group, the decision maker(s) had to have a certain level of authority to make the bidding decision. The third category was mentioned as courses that were offered in the companies on e.g. writing proposals or negotiating.

The most importance criterion for choosing a decision maker was named as their experience which was mentioned by six of nine interviewees. Of similar importance (mentioned by five interviewees) and connected to experience is the category of delegation in the company which was a further important criterion for the choice of the bidding decision maker. The completion of courses was mentioned by two interviewees, both highlighted that this was only a supportive aspect; the decision maker(s) would not be chosen based on the courses they had completed.

\subsubsection{Obtaining the price bid}

The calculation of the price bid, in other words the assessment of the monetary values to be included in the bid, can be categorised in two different approaches: 'cost + profit margin $=$ price' and price-focused process. The 'equation' of the first group is a simplified depiction of the approach, most of the interviewees (seven out of nine) utilised in their bidding process. To the interpretation of the cost estimate a profit margin is added which can include a contingency, an administration margin and the consideration of inflation. Two of the interviewees stated that their process was focused on the price and the costs were not considered separate from that. This means that the price is considered in different steps within the bidding company regarding to either its suitability to the customer's stated budget (one of the interviewees) or to strategic evaluation of the market situation and the customer needs (the other interviewee).

Following this question was the assessment of the minimum price bid underneath which the bidder would not accept the contract. The interviewees agreed that there was not a 
usual process to calculate this price before the tendering or negotiation process. However, the valuation of the minimum price can be categorised as: 'cost + minimum profit', available alternatives and the potential of follow-on work.

Six of the nine interviewees stated that they were prepared to reduce their profit in the bidding situation (first group). This includes the situation of no profit and excludes a deliberate loss. One of the interviewees of that category stated that the price bid communicated to the customer would be the minimum acceptable price. Two of the interviewees said that the minimum price varied according to the available alternatives in the economic situation at the time of bidding (second group). This comparison could include not achieving an agreement. In the third group, the minimum price was dependent on strategic aims such as the possibility of receiving future contracts with this customer. Two of the interviewees belonged to this category, one of which stated it in addition to the best available alternative.

\subsubsection{Acceptance of a contract with a high risk of making a loss}

To assess other strategic aspects that may influence the bidding decision, the interviewees were asked if they had agreed to contracts which deliberately made a loss. Of the nine interviewees five stated that they would not accept such a contract, four said they had done. The answers to the question can be categorised as depicted in Table 6 .

Table 6 shows that there was just one reason mentioned by the interviewees regarding the refusal of a contract with a high probability of making a loss which was typically connected to company policy or the usual conduct in the market sector. However, for the acceptance, the answers could be divided into three categories, namely the bidding company's long term gains, the possibility of eliminating competition and the profile of the customer as a client. The interviewees that stated that they would accept such a contract usually mentioned multiple aims of these categories. 
Table 6: Interviewees' reasoning behind refusing or accepting a contract with high probability of making loss

\begin{tabular}{|c|c|c|}
\hline Reply & Reasoning & $\begin{array}{l}\text { Number of } \\
\text { interviewees }\end{array}$ \\
\hline Refusal & $\begin{array}{l}\text { No deliberate loss: depending on the company policy and the situation in } \\
\text { the market sector, the company was not considering to deliberately making } \\
\text { a loss. The price would be reduced in a realistically achievable process; } \\
\text { further reductions of the price were not possible. }\end{array}$ & 5 \\
\hline \multirow{3}{*}{ Acceptance } & $\begin{array}{l}\text { Long term gains: One strategic consideration was mentioned as the } \\
\text { possibility of long term gains through the acceptance of a contract with a } \\
\text { high probability of making a loss. Such future gains can include follow-on } \\
\text { work and further contracts with the client. }\end{array}$ & 3 \\
\hline & $\begin{array}{l}\text { Eliminate competition: Another aim with a contract including a loss could } \\
\text { be to eliminate the competition for this market sector or this particular } \\
\text { customer. }\end{array}$ & 2 \\
\hline & $\begin{array}{l}\text { High profile customer: If a particular customer was a major client of the } \\
\text { bidding company, this customer could be given 'special prices'. This aspect } \\
\text { was mentioned in connection to the two other strategic aims of accepting a } \\
\text { contract with a high probability of making a loss. }\end{array}$ & 1 \\
\hline
\end{tabular}

\section{Discussion}

The pricing process used by most of the interviewees was cost based which confirms the assumptions of previous studies [Avlonitis and Indounas, 2005]. Furthermore, a connection could be observed between the complexity of the contract and the bidding process which determines the level of negotiation between customer and possible supplier. It was found that the more complex a service contract, the closer the two parties work together throughout the bidding process. This confirms the research of Bajari et al. [2008]. However, a connection between the payment method and the bidding process as described by Bajari et al. [2008] was not confirmed in this study.

The cost estimate usually included uncertainty in the form of a cost range. If uncertainty was not explicitly included in the cost estimate, it was usually based on specific assumptions which would be reassessed during the following pricing process. The uncertainty in a pricing decision was usually considered in the process (in one way or another). Where possible this uncertainty was reduced, for example if the service requirements were not clear 
or vague, the bidding company usually had the opportunity to receive further information from the customer through negotiation.

Focusing on certain sources of uncertainty such as the competitors and the customer, the bidding company was usually not ignorant about these factors and their possible influence on the decision outcome. The identity of the competitors was usually known to the bidding company or could be assessed during the process of compiling the bid. This means that the competitors' profile and available resources can be taken into account in the process. Similarly, the customer's bidding strategy was either known or assessable. This means that the customer's evaluation of the service price and quality as well as other criteria is or can be known at least vaguely. Particularly customers that the bidding company had had a previous connection with to build up trust [Johnson and Grayson, 2005] form an important source of information and reduce the level of uncertainty.

The presented interview study found that the pricing decision under uncertainty was based on the subjective evaluation of the decision maker(s) regarding the consideration of different uncertainties. As indicated by literature in uncertainty research [Samson et al., 2009; Thunnissen, 2003], the terms uncertainty and risk are hard to define and distinguish comprehensively. This was confirmed by the interview study, some interviewees used examples to overcome this difficulty. For the identification of uncertainties that may influence the considered service contracts, subjective methods were prominent while for their management subjective methods are used but often supported by objective methods such as Monte Carlo modelling. This suggests that there is a need for models to support the decision process in practice. Another aspect to overcome the uncertainty arising from individual assessment was the involvement of a decision team.

Limitations of this empirical study include the small set of participants. However, the results are to be understood as indicative as opposed to a comprehensive characterisation of 
the current bidding situation for service contracts. With this purpose, they identify common patterns of approaching the decision problem, aspects and opportunities for further improvement and possibilities for offering support to the decision maker.

\section{Summary and conclusions}

This paper presented an interview study with industrialists from manufacturing companies facing the change of market structures towards servitisation. The study gave insights into the typically available information. Table 7 shows a summary of the findings.

The findings from the interview study described in this paper show the influences and considerations during the decision-making process at the competitive bidding stage for service contracts. This forms a first step towards a more elaborate understanding of the processes involved in practice and of the development of a support for industry to make more informed decisions and secure the profitability of their service contracts.

In addition to the aim of the presented interview study, namely the identification of the available information for manufacturing companies at the competitive bidding stage for service contracts, the study delivered further results. For example, it was found that costing information is typically communicated within the company either in tabular form as a cost breakdown or in a graphical form as a three-point estimate. Recent research found that these approaches are suboptimal in raising the decision maker's awareness of the uncertainty connected to the cost forecast [Kreye et al., 2012]. Thus, further research is necessary to support industry in adapting optimal approaches for the communication of the uncertainty associated with the decision making problem. 
Table 7: Summary of research findings of interview study

\begin{tabular}{|c|c|c|}
\hline Area & Focus of investigation & Findings \\
\hline \multirow{3}{*}{$\begin{array}{l}\text { Uncertainty and } \\
\text { risk }\end{array}$} & $\begin{array}{l}\text { Definition and meaning } \\
\text { of the two terms }\end{array}$ & $\begin{array}{l}\text { Differences between different companies, some having } \\
\text { corporate-wide definitions, other applying individual } \\
\text { definitions }\end{array}$ \\
\hline & $\begin{array}{l}\text { Sources for identification } \\
\text { of uncertainties }\end{array}$ & $\begin{array}{l}\text { Experience of project manager or team, in more rare events } \\
\text { also risk management handbooks or databases }\end{array}$ \\
\hline & $\begin{array}{l}\text { Management tools for } \\
\text { uncertainty }\end{array}$ & $\begin{array}{l}\text { Monte Carlo Analysis, Sensitivity Analysis, management } \\
\text { through project manager or team }\end{array}$ \\
\hline \multirow[t]{2}{*}{ Bidding context } & Bidding process & $\begin{array}{l}\text { One-bid process, two-bid process with or without negotiation } \\
\text { or just negotiation with customer }\end{array}$ \\
\hline & Payment method & Fixed prices, cost-based payment or payment on completion \\
\hline \multirow{3}{*}{ Input information } & Cost estimate & $\begin{array}{l}\text { Presentation in table as cost breakdown or three-point } \\
\text { estimate or in a graph as a three-point estimate or an s-curve } \\
\text { Inclusion of uncertainty either as variation in input data, } \\
\text { quantification of qualitative uncertainty (i.e. "what can go } \\
\text { wrong”) or not executed } \\
\text { Interpretation of the cost estimate as is, as a point estimate or } \\
\text { as a range estimate } \\
\text { Influencing uncertainties named as customer-related, } \\
\text { competitor-related, cost-estimation, economic or other } \\
\text { uncertainties }\end{array}$ \\
\hline & Customer & $\begin{array}{l}\text { Customer's budget limitations and evaluation criteria either } \\
\text { communicated with tender or assessable by competing } \\
\text { suppliers through "getting-to-know-the-client” phase } \\
\text { Previous experience and past relationship with customer most } \\
\text { important source of information for bidding decision } \\
\text { Customer's future needs can influence the service offer }\end{array}$ \\
\hline & Competitors & $\begin{array}{l}\text { Identity may be known depending on bidding process and the } \\
\text { supplier's experience in the market sector } \\
\text { Competitors' cost estimates are not known, however a } \\
\text { "ballpark” may be deduced } \\
\text { Competitors' available technology or knowledge assessable } \\
\text { for decision maker }\end{array}$ \\
\hline \multirow{3}{*}{ Bidding strategy } & Choice of decision maker & $\begin{array}{l}\text { Based on experience, also on delegation in the company or } \\
\text { completion of bidding courses }\end{array}$ \\
\hline & Obtaining price bid & $\begin{array}{l}\text { Cost-based or price-focuses approach } \\
\text { Minimum price obtained through the addition of minimum } \\
\text { profit to estimated cost, the assessment of the available } \\
\text { alternatives or the potential of follow-on work with the } \\
\text { customer }\end{array}$ \\
\hline & $\begin{array}{l}\text { Acceptance of loss- } \\
\text { inducing contracts }\end{array}$ & $\begin{array}{l}\text { Refusal based on company policy or acceptance based on } \\
\text { possible long-term gains, the aim of eliminating competition } \\
\text { or the high profile of the specific customer }\end{array}$ \\
\hline
\end{tabular}

The findings described in this paper can be used for future research to develop a uncertainty model for competitive bidding. This uncertainty model can include the information connected 
to the customer and competitors to determine the manufacturing company's probability of winning the service contracts and its probability of making a profit. This information supports the decision makers at the bidding stage to make a more informed decision, evaluate the level of risk with their pricing decision and, thus, ensure the long-term profitability and sustainability of their business.

\section{References:}

AFUAH, A., 2009. Strategic Innovation - New Game Strategies for Competitive Advantage, New York, NY, USA, Routledge.

ARAUJO, L. \& SPRING, M., 2006. Services, Products, and the Institutional Structure of Production. Industrial Marketing Management, 35(7), 797-805.

AVLONITIS, G. J. \& INDOUNAS, K. A., 2005. Pricing Objectives and Pricing Methods in the Services Sector. Journal of Services Marketing, 19(1), 47-57.

Babcock, 2012. Australian Anzac Support Contract Win [online]. Available from: http://www.babcock.co.uk/media-centre/babcock-australian-anzac-support-contract/ [accessed 04 May 2012].

BAINES, T., LIGHTFOOT, H. \& SMART, P., 2011. Servitization within manufacturing: Exploring the provision of advanced services and their impact on vertical integration. Journal of Manufacturing Technology Management, 22(7), 947-954.

BAJARI, P., MCMILLAN, R. \& TADELIS, S., 2008. Auctions Versus Negotiations in Procurement: An Empirical Analysis. Journal of Law, Economics, \& Organization, 25(2), 372-399.

BANDINELLI, R. \& GAMBERI, V., 2011. Servitization in oil and gas sector: outcomes of a case study research. Journal of Manufacturing Technology Management, 23(1), 87-102.

BHASKARAN, S. R. \& RAMACHANDRAN, K., 2011. Managing technology selection and development risk in competitive environments. Production and Operations Management, 20(4), 541-555.

BOLTON, R. N., LEMON, K. N. \& BRAMLETT, M. D., 2006. The Effect of Service Experiences over Time on a Supplier's Retention of Business Customers. Management Science, 52(12), 1811-1823.

BUBSHAIT, A. A. \& ALMOHAWIS, S. A., 1994. Evaluating the General Conditions of a Construction Contract. International Journal of Project Management, 12(3), 133-136.

CAI, G., CHAO, X. \& LI, J., 2009. Optimal reserve prices in name-your-own-price auctions with bidding and channel options. Production and Operations Management, 18(6), 653-671. 
CHANETON, J. M. \& VULCANO, G., 2011. Computing bid prices for revenue management under customer choice behavior. Manufacturing and Service Operations Management, 13(4), 452470.

CHAPMAN, C. B., WARD, S. C. \& BENNELL, J. A., 2000. Incorporating Uncertainty in Competitive Bidding. International Journal of Project Management, 18(5), 337-347.

CHRISTOFFERSEN, P. F., 1998. Evaluating Interval Forecasts. International Economic Review, 39(4), 841-862.

CIOFFI, D. F., 2005. A Tool for Managing Projects: An Analytic Parameterization of the S-curve. International Journal of Project Management, 23(3), 215-222.

FARGIER, H. \& SABBADIN, R., 2005. Qualitative Decision under Uncertainty: Back to Expected Utility. Artificial Intelligence, 164(2005), 245-280.

FREEDMAN, A. M. (1988): A Price That's Too Good May Be Bad. In: The Wall Street Journal, 15 November, pp.

FRIEDMAN, L., 1956. A Competitive-Bidding Strategy. Operations Research, 4(1), 104-112.

GADREY, J., 2000. The Characterization of Goods and Services: An Alternative Approach. Review of Income \& Wealth, 46(3), 369-387.

GIORDANI, P. \& SÖDERLIND, P., 2003. Inflation Forecast Uncertainty. European Economic Review, 47(6), 1037-1059.

GOH, Y. M., NEWNES, L. B., MILEHAM, A. R., MCMAHON, C. A. \& SARAVI, M. E., 2010. Uncertainty in Through-Life Costing - Review and Perspectives. IEEE Transactions on Engineering Management, 57(4), 689 - 701.

GUO, P., LIU, J. J. \& WANG, Y., 2009. Intertemporal service pricing with strategic customers. Operations Research Letters, 37(6), 420-424.

HARRINGTON JR., J. E., 2009. Games, Strategies, and Decision Making, New York, NY, USA, Worth Publishers.

HYTÖNEN, H., 2005. A Model for Value-based Pricing of Industrial Services. Masters Thesis. Helsinki University of Technology.

JOHNSON, D. \& GRAYSON, K., 2005. Cognitive and Affective Trust in Service Relationships. Journal of Business Research, 58(4), 500-507.

KREYE, M. E., 2011. Uncertainty Analysis in Competitive Bidding for Service Contracts. PhD Thesis. University of Bath.

KREYE, M. E., GOH, Y. M., NEWNES, L. B. \& GOODWIN, P., 2012. Approaches of Displaying Information to Assist Decisions under Uncertainty. Omega - International Journal of Management Science, 40(6), 682-692.

LEHMAN, D. H., 1986. Technique for Lowering Risks During Contract Negotiations. IEEE Transactions on Engineering Management, 33(2), 79-81. 
LI, H. \& GRAVES, S. C., 2012. Pricing decisions during inter-generational product transition. Production and Operations Management, 21(1), 14-28.

LI, J. \& WANG, Y., 2010. Supplier competition in decentralized assembly systems with pricesensitive and uncertain demand. Manufacturing and Service Operations Management, 12(1), 93-101.

LOEWENSTEIN, G. E. \& PRELEC, D., 1993. Preferences for Sequences of Outcomes. Psychological Review, 100(1), 91-108.

LUCAS, M. T. \& KIRILLOVA, O. M., 2011. Reconciling the resource-based and competitive positioning perspectives on manufacturing flexibility. Journal of Manufacturing Technology Management, 22(2), 189-203.

MONROE, K. B., 2002. Pricing: Making Profitable Decisions, New York, NY, USA, McGrawHill/Irwin.

NELLORE, R., 2001. Validating Specifications: A Contract-based Approach. IEEE Transactions on Engineering Management, 48(4), 491-504.

NEUGEBAUER, T. \& PEZANIS-CHRISTOU, P., 2007. Bidding Behavior at Sequential First-price Auctions With(out) Supply Uncertainty: A Laboratory Analysis. Journal of Economic Behavior \& Organization, 63(2007), 55-72.

PATTON, M. Q., 2002. Qualitative Research and Evolution Methods, Thousand Oaks, CA, USA, Sage.

REXFELT, O. \& ORNÄS, V. H. A., 2009. Consumer acceptance of product-service systems: Designing for relative advantages and uncertainty reductions. Journal of Manufacturing Technology Management, 20(5), 674-699.

ROBINSON, H., SEGAL, J. \& SHARP, H., 2007. Ethnographically-informed Empirical Studies of Software Practice. Information and Software Technology, 49(6), 540-551.

2011. Submarines Propulsion [online]. Available from: http://www.rollsroyce.com/marine/about/market_sectors/submarines/submarines_propulsion/ [accessed 25/10/2011].

ROWLEY, J., 1997. Beyond Service Quality Dimensions in Higher Education and Towards a Service Contract. Quality Assurance in Education, 5(1), 7-14.

RUBINSTEIN, A., 1998. Modeling Bounded Rationality, Cambridge, MIT Press.

SAMSON, S., RENEKE, J. A. \& WIECEK, M. M., 2009. A Review of Different Perspectives on Uncertainty and Risk and an Alternative Modeling Paradigm. Reliability Engineering \& System Safety, 94(2), 558-567.

SAUNDERS, M. N. K., LEWIS, P. \& THORNHILL, A., 2012. Research Methods for Business Students, Harlow, UK, Financial Times Prentice Hall.

SCHOENHERR, T. \& MABERT, V. A., 2008. The use of bundling in B2B online reverse auctions. Journal of Operations Management, 26(1), 81-95. 
SHOSTACK, G. L., 1987. Service Positioning Through Structural Change. Journal of Marketing, 51(1), 34-43.

SKAGGS, B. C. \& YOUNDT, M., 2004. Strategic Positioning, Human Capital, and Performance in Service Organizations: A Customer Interaction Approach. Strategic Management Journal, 25(1), 85-99.

SONG, Y.-I., LEE, D.-H., LEE, Y.-G. \& CHUNG, Y.-C., 2007. Managing uncertainty and ambiguity in frontier R\&D projects: A Korean case study. Journal of Engineering and Technology Management, 24(2007), 231-250.

SOŠIĆ, G., 2011. Impact of demand uncertainty on stability of supplier alliances in assembly models. Production and Operations Management, 20(6), 905-920.

STECHER, J. D., 2008. Subjective Information in Decision Making and Communication. In: ABDELLAOUI, M. \& HEY, J. D. (Eds.) Advances in Decision Making Under Risk and Uncertainty. Berlin Heidelberg, Springer-Verlag, pp. 49-62.

SWINNEY, R. \& NETESSINE, S., 2009. Long-Term Contracts Under the Threat of Supplier Default. Manufacturing \& Service Operations Management, 11(1), 109-127.

TAY, A. S. \& WALLIS, K. F., 2000. Density Forecasting: A Survey. Journal of Forecasting, 19(4), 235-254.

TEDDLIE, C. \& TASHAKKORI, A., 2009. Foundations of Mixed Methods Research, Thoudand Oaks, CA, USA, Sage.

THUNNISSEN, D. P. (2003): Uncertainty Classification for the Design and Development of Complex Systems. In: PMC2003 - 3rd Annual Predictive Methods Conference, 16-17 June, Newport Beack, CA, USA.

TSENG, F.-S., TANG, K., MOSKOWITZ, H. \& PLANTE, R., 2009. Maintenance Outsourcing Contracts for New Technology Adoptions. IEEE Transactions on Engineering Management, 56(2), 203-218.

TULLOCH, A., 1980. Is Competitive Price Bidding for Professional Services Practical? ASCE Journal of Professional Issues in Engineering, 106(1), 57-61.

WANG, W.-C., DZENG, R.-J. \& LU, Y.-H., 2007. Integration of Simulation-based Cost Model and Multi-criteria Evaluation Model for Bid Price Decisions. Computer-Aided Civil and Infrastructure Engineering, 22(3), 223-235.

YAGER, R. R., 1999. A Game-theoretic Approach to Decision Making Under Uncertainty. International Journal of Intelligent Systems in Accounting, Finance \& Management, 8(1999), 131-143. 